\title{
Tek Maddeli Narsisizm Ölçeği’nin Kısıtları ve Eleştirileri
}

\author{
Emrah ÖZSOYl
}

\section{Özet}

Narsisizm son dönemlerde psikolojinin çeşitli alt dallarında ve örgütsel davranış araştırmalarında yaygın bir şekilde çalışılmaya başlanmıştır. Narsisizm farklı sınıflandırmalar ve buna bağlı olarak çeşitli boyutlar kapsamında incelenen bir yapıdır. Bu kapsamda klinik araştırmalarda kişilik bozukluğu ya da patolojik narsisizm ayrımlarında, sosyal psikoloji ve örgütsel psikoloji araştırmalarında ağırlıklı subklinik düzeyde incelenmektedir. Ek olarak kırılgan, büyüklenmeci (grandiose), normal, hipersensitif ve toplumsal narsisizm sinıflandırmaları da bulunmaktadır. Her bir sinıflandırma kapsamında da farklı boyutlar incelenmektedir. Bu sebeple narsisizmin tek madde ile ölçülmesi zorlaşmaktadır. Bu çalışmada Konrath, Meier ve Bushman (2014) tarafından geliştirilen ve Özsoy vd., (2017) tarafindan Türk kültürüne uyarlanan tek maddeli narsisizm ölçeğinin (Single Item Narcissim Scale: SINS) Türkçe Formunun (SINS-T), psikometrik özelliklerine ilişkin ek bulgu elde etmek amaçlanmıştır. Bu doğrultuda iki ayrı çalışmada (çalışma $1 \mathrm{n}=349$, çalışma $2 \mathrm{n}=236$ Toplam $\mathrm{N}=$ 585), SINS-T'nin psikometrik özellikleri incelenmiştir. Çalışma 1'de akademisyen örnekleminde Karanlık Üçlü bileşenleri (Narsisizm, Makyavelizm ve Psikopati) ile; Çalışma 2'de hetorojen bir çalışan grubu örnekleminde Beş faktör kişilik özellikleri ve NPI-16 değişkenleri ile SINS-T'nin psikometrik özellikleri incelenmiştir. Söz konusu değişkenlerle SINS-T'nin yakınsak ve ayırt edici geçerliği (nomolojik ağlar ve çok özellikli çoklu metot yaklaşımı ile) sınanmıştır. Her iki çalışmada da erkeklerin skoru (SINS-T) kadınlardan daha yüksek tespit edilmiştir. Her iki araştırmada da SINST’nin psikometrik özellikleri geçerlik beklentilerini belli bir düzeyde karşılamıştır. Ancak genel olarak tek maddeli ölçeklerin kısıtları, narsisizm özelinde bir takım kısıtlar ve bu araştırmanın kısıtlarına dayanarak, SINS-T'nin mevcut narsisizm ölçeklerine rakip olarak değerlendirilmemesi gerektiği, ancak alternatif bir ölçek olarak değerlendirilebileceği düşünülmektedir. Tartışma bölümünde araştırma bulguları yorumlanmış, çalışmanın ve ölçeğin kısıtları ve eleştirileri vurgulanmıştır.

Anahtar Kelimeler: Narsisizm, Tek Maddeli Narsisizm Ölçeği, Psikometrik Özellikler, Kısıtlar, Eleştiriler

\section{Limitations and Criticisms of Single Item Narcissism Scale}

\begin{abstract}
Narcissism has recently been widely studied in the various subfields of psychology and in organizational behavior research. Narcissism is a structure that is studied under different classifications and related to this with various dimensions. In this context, it is examined at level of personality disorder or pathological narcissism in clinical research and at the subclinical level in social psychology and organizational psychology research. In addition, there are classifications of vulnerable, grandiose, normal, hypersensitive, collective narcissism. Within each classification, different aspects of narcissism are examined. Therefore, it is difficult to measure narcissism with a single item. In this study, it is aimed to obtain further findings on the psychometric properties of the Turkish version of Single Item Narcissism Scale (SINS-T) which was developed by Konrath, Meier, \& Bushman (2014), and adapted into Turkish culture by Özsoy et al. (2017). In this direction, psychometric properties of SINS-T were investigated in two separate studies (study $1 \mathrm{n}=349$, study $2, \mathrm{n}=236$, Total $\mathrm{N}=585$ ). In study 1, with Dark Triad components (i.e., narcissism, Machiavellianism, and psychopathy) on sample group of academicians; In the study 2, with five factor personality traits and NPI-16, on a heterogeneous employee group, the psychometric properties of SINS-T has been examined. With those variables the convergent and discriminant validity of SINS-T (with nomological networks and multimethod multi-method approach) were examined. In both studies, the score of SINS-T of men was higher than women. In both studies, the psychometric properties of SINS-T met the expectations of validity at a certain level. However, based on the limitations of single item scales, narcissism-specific constraints and the limitations of current research, it thought that SINS-T should not be considered as a competitor to current narcissi scales but it can be used as an alternative scale. In the discussion section, the findings of the study were interpreted and the limitations and criticisms of the study and SINS-T were emphasized.
\end{abstract}

Key words: Narcissism, Single Item Narcissism Scale, Psychometric Properties, Limitations, Criticisms

1 Dr. Öğr. Üyesi, Sakarya Üniversitesi, İşletme Fakültesi, Yönetim ve Organizasyon Bölümü, eozsoy@sakarya.edu.tr 


\section{Giriş}

Tek maddeli ölçeklerin kullanımı genellikle iki şekilde olmaktadır. Bunlardan ilki (a) yaş, eğitim durumu, daha önceki işlerin sayısı gibi hususlarda tek bir soru ile öz-bildirim yöntemiyle katılımcılara ait birtakım özellik ve gerçeklerin ölçümüdür ve bu ölçümler genellikle kabul görmektedir. İkincisi ise (b) psikolojik yapıların ölçümüdür. Psikolojik yapıların tek madde ile ölçümü ise hakemlik sürecinde ağılıklı olarak "ölümcül hata" (fatal error) olarak değerlendirilmektedir (Wanous, Reichers ve Hudy, 1997: 247). Sackett ve Larson' a (1990) göre (akt., Wanous, Reichers ve Hudy, 1997: 247), eğer ölçülecek yapı ya da değişken çok dar, anlaşılması kolay ve tek boyutlu ise bu durumda "tek maddeli ölçeklere" başvurulabileceği vurgulanmaktadır. Ancak ölçülecek yapı çok boyutlu (multi-dimensional) bir yapı ise (örneğin kişilik özellikleri gibi), çok boyutlu ,ölçeklerin kullanımı daha uygun görülmektedir (Wanous, Reichers ve Hudy, 1997). Bu sebeple çok boyutlu bir kişilik özelliği olan narsisizmi tek madde ile ölçen tek maddeli narsisizm ölçeğinin (Single Item Narcissim Scale: SINS) Türkçe formunun (SINS-T) psikometrik özelliklerinin detaylıca incelenmesi gerektiği düşünülmektedir.

Narsisizm son dönemlerde psikolojinin çeşitli alanlarında yaygın bir şekilde çalışılmaktadır. Özellikle son 10 yılda örgütsel davranış araştırmalarında da narsisizm üzerinde yapılan çalışmalar giderek artmaktadır (Blair, Hoffman ve Helland, 2008; Campbell vd., 2010; Chatterjee ve Hambrick, 2007; Grijalva ve Harms, 2014). Narsisizm üzerinde yapılan çalışmalarda kritik hususlardan biri de narsisizmin ölçümü üzerine gerçekleşmektedir. Narsisizmin ölçümünde 1980'lere kadar önemli eksikliklerin olduğu görülmektedir. Narsisizmin ölçümünde ilk çalışmalardan biri, Raskin ve Hall (1979) tarafından 220 adet narsisizm ile alakalı maddenin bir araya getirilmesi ile yürütülmüştür. Raskin ve Hall (1979) 220 maddeyi, 54 maddeli bir yapıya (Narcisistic Personality Inventory-54: NPI54) indirgemiştir. Bu ölçek daha sonra Raskin ve Terry (1988) tarafından 40 maddeye (NPI-40) düşürülmüştür. Daha sonra NPI-40'in 16 maddeli, NPI-16 (Ames vd., 2006; Kubarych vd., 2004) ve 13 maddeli, NPI-13 (Gentile vd., 2013) kısaltılmış versiyonları da geliştirilmiştir. 2010 ve sonrasında ise narsisizmin 4 maddeli (Dark Triad Dirty Dozen-DTDD) (Jonason ve Webster, 2010), 9 maddeli (Short Dark Triad, SD3) (Jones ve Paulhus, 2013) ve tek maddeli versiyonu (Single Item Narcissim Scale, SINS) (Konrath, Meier ve Bushman, 2014) da geliştirilmiştir. Ayrıca Patolojik Narsisizm Envanteri (PNE) (Pincus vd., 2009), Hipersensitif Narsisizm Ölçeği (Hendin ve Cheek, 1997), beş faktör narsisizm ölçeği (Glover vd., 2012) ve Toplumsal Narsisizm Ölçeği (Gebauer vd., 2012) gibi ölçüm araçları da kullanılmaktadır. Görüldüğü gibi narsisizmin ölçümünde çok sayıda ölçek alternatifi ve çalışma bulunmaktadır. Her bir ölçeğin kullanım amacı, kapsadığı boyutlar ve psikometrik özellikleri farklılık göstermektedir. Söz konusu ölçeklerin psikometrik özelliklerinin incelenmesine yönelik çalışmalar da halen devam etmektedir. Bu çalışmada daha önceden Özsoy vd., (2017) tarafından Türkçe'ye uyarlanan tek maddeli narsisizm ölçeğinin psikometrik özelliklerinin detaylıca incelenmesi amaçlanmıştır. Çünkü sadece narsisizm için değil genel olarak her hangi bir yapıyı tek 
madde ile ölçmek önemli bir kısıt ve eleştiri konusudur (Diamantopoulos vd., 2012; Lucas ve Donnellan, 2011). Bu sebeple söz konusu ölçeklerin psikometrik özelliklerinin detaylıca incelenmesi ve kısıtlarının belirgin bir şekilde ortaya konması gerekmektedir. Araştırmanın gerçekleştirilmesindeki bir diğer gerekçe ise Özsoy vd., (2017) ölçeğin geçerliğini sadece öğrenci örneklemi üzerinde test etmesidir. Bu sebeple bu çalışmada farklı örneklem grupların da (2 ayrı örneklem grubu) ve farklı ölçüt geçerliği yapıları ile (Narsisizm, Makyavelizm, Psikopati, Beş Faktör Kişilik Özellikleri) tek maddeli narsisizm ölçeğinin psikometrik özelliklerinin incelemesi ve ölçeğin kısıtlarının belirlenmesi amaçlanmıştır.

Çalışmada ilk olarak kısaca narsisizm kavramı tanımlanmış daha sonra narsisizm ölçümü üzerine geliştirilmiş ölçekler ana hatları ile sunulmuştur. Daha sonra tek maddeli narsisizm ölçeğine ilişkin (ölçeğin geliştirilmesi, psikometrik özellikleri) mevcut çalışmaların bulguları paylaşılmıştır. Bunu takiben araştırmanın arka planı kapsamında tek maddeli narsisizm ölçeğinin psikometrik özelliklerinin testine ilişkin beklentiler setine yer verilmiştir. Son olarak 2 ayrı örneklem grubu üzerinde elde edilen bulgular paylaşılmış ve tartışma bölümünde ölçeğin değerlendirme ve eleştirisi yapılmıştır.

\section{Narsisizm}

Narsisizm, Amerikan Psikiyatri Birliği tarafından yayımlanan Mental Ve Zihinsel Bozuklukların Tanısal ve Sayımsal El Kitabı'nın (Diagnostic and Statistical Manual of Mental Disorders) üçüncü basımından itibaren bir kişilik bozukluğu olarak ele alınmaktadır (APA, 2013). Ancak örgütsel psikoloji çalışmalarında kişilik bozukluğu düzeyinde değil, ağırlıklı olarak subklinik düzeyde narsisizm incelenmektedir (Özsoy,2019). Nitekim narsisizmin ölçümüne ilişkin geliştirilmiş ölçeklerin çoğu da klinik teşhis koyma kaygısı ve iddiası gütmemektedir (örn., Raskin ve Terry, 1980; Jonason ve Webster, 2010). Narsisizm en yalın haliyle bireyin kendisine hayran ve aşık olmasını ifade etmektedir. Narsistler yüksek düzeyde kendini beğenmiş, hava atmayı gösteriş yapmayı ve ilgi odağı olmayı seven kişilerdir. Bu kişiler kendilerini eşsiz görüp, çoğu durumunda çevrelerindeki insanları küçümseme, onlara tepeden bakma, onlar üzerinde otorite kurma eğilimindedirler (APA, 2013; Konrath, 2008; Özsoy, 2018; Özsoy, 2019; Raskin ve Terry, 1988; Rauthmann ve Kolar, 2012). Narsisizmin gelişiminde çocukluk döneminde aşırı baskı altında kalma ya da aşırı şımartılma, giderilmemiş temel psikolojik ihtiyaçlara (sevilme, takdir görme, onaylanma) yönelik geliştirilen savunma mekanizması sonucunda bireyin şişirilmiş ve gerçekçi olmayan bir benlik inşa etmesi gibi nedenler yer almaktadır. Esasen narsisizmi tetikleyen en belirgin nedenlerden biri kişinin özünde kendisini eksik ve yetersiz hissetmesidir.

\section{Narsisizmin ölçümü}

Aşağıda narsisizmin ölçümü için geliştirilmiş ölçekler ve bu ölçeklerin geliştirilme süreçleri hakkında ana hatları ile bilgi sunulmuştur. Bu kapsamda Narsistik Kişilik Envanteri (Narcissistic 
Personality Inventory) ve versiyonları (NPI-16, NPI-13), Beş Faktör Narsisizm Ölçeği, Kısaltılmış Karanlık Üçlü ölçeklerinin narsisizm boyutları (Dirty Dozen Dark Triad: DTDD ve Short Dark Triad: SD3) ve tek maddeli narsisizm ölçeğine (Single Item Narcissism Scale: SINS) ilişkin kısa bilgiler sunulmuştur.

\section{Narsistik Kişilik Envanteri}

NPI-54 ve NPI-40: Narsisizmin ölçümünde ilk çalışmalardan biri Raskin ve Hall (1979) tarafından 220 adet narsisizm ile alakalı maddenin bir araya getirilmesi ile gerçekleştirilmiştir. Raskin ve Hall (1979) 220 maddeyi, 54 maddeli bir yapıya (Narcisistic Personality Inventory-54: NPI-54) indirgemiştir. Bu ölçek daha sonra Raskin ve Terry (1988) tarafından 40 maddeye (NPI-40) indirgenmiştir. NPI-40 kişinin kendinin işaretlediği, narsist olma ve narsist olmama özellikleri olarak eşleştirilmiş 40 madde çiftinden oluşan bir yapıdadır. İlerleyen çalışmalarda ölçeğin 7 ila 4 boyutlu versiyonları önerilmiştir. Fakat ölçeğin psikometrik özelliklerine ilişkin sorunları tam olarak çözülmüş durumda değildir (Brown vd., 2009). NPI geliştirildikten sonra yapılan iki geçerlik çalışmasında Emmos $(1984,1987) 37$ maddeden oluşan ve dört boyutlu bir ölçek önermiştir. Emmons (1984) ilk çalışmasında NPI'nin liderlik/otorite, üstünlük/kibir, kendine odaklılık/hayranlık ve sömürücülük/hak iddia etme boyutlarına indirgenip kullanılabileceğini ileri sürmüştür. Bunu takiben ikinci bir çalışmada (Emmos, 1987) aynı boyutlar elde edilmiştir. NKE-40'ın Türkçeye uyarlaması Kızıltan (2000) tarafından yapılmıştır. Kızıltan (2000) geçerlik ve güvenilirlik çalışmasında ölçekten 4., 12., 13., 17., 28. ve 35. maddeleri çıkarmıştır ve kalan 34 maddenin 7 boyutta toplandığını tespit etmiştir.

NPI-16 ve NPI-13: Kubarych vd. (2004) np1-40'1n 16 eşli maddeden oluşan bir versiyonunu (NPI-16) önermiştir. Buna göre NPI-16 güç, teşhircilik ve özel bir insan olmak boyutlarından oluşan genel narsisizm yapısını ölçmektedir. Ames vd. (2006) NPI'nin uzun formunun etkin sonuçlar vermeyeceği örneklemlerde kullanılabilmesini için kısa formunu önermiştir. Araştırmada 40 madde çiftinden oluşan ölçek 16 madde çiftine indirgenmiştir. Araştırmacılar maddeleri ölçekten çıkarırken "Görünüş Geçerliği” ni (Face validity) takip etmiştir. Buna göre araştırmalar narsisizm ile ilişkili ancak farklı yapılar olduklarını düşündükleri liderlik öz-yeterliliği, kibir ve kendini beğenme ile ilişkili maddeleri ölçekten çıkarmıştır. Örneğin "kendimi iyi bir lider olarak görüyorum” maddesi ölçekten çıkarılmıştır. Bunun yerine araştırmacılar 16 maddelik ölçeğe 40 maddelik ölçekten madde seçerken "ilgi odağı olmayı severim” gibi narsisizm ile doğrudan ilişkili olduğunu düşündükleri maddeleri dâhil etmiştir. Bu ölçek Atay (2009) tarafindan Türk kültürüne uyarlanmıştır. Ayrıca Gentile vd. (2013) narsisizmin ölçümü için NKE-13'ü önermiştir. Bu ölçeğin Ames vd. (2006) tarafindan önerilen NKE16 ile uyumlu olduğu test edilmiştir.

Beş Faktör Narsisizm Ölçeği: Ölçeğin uzun formu 143 maddeden oluşmaktadır. Kısa formu (Glover vd., 2012) ise 60 maddelidir. Ölçek temelde kırılgan ve büyüklenmeci narsisizmi ölçmektedir ve 15 alt boyuttan oluşmaktadır. Bu boyutlar; büyüklenme hayalleri, empati eksikliği, güvensizlik, hak 
iddia etme, hayranlık ihtiyacı, kibir, liderlik/otorite, maceraperestlik, manipülatiflik, onay arayıcılık, sömürücülük, tepkisel öfke/öfke, teşhircilik, umursamazlık ve utançtır (Ekşi, 2016). Ölçeğin Türk kültürüne uyarlaması Ekşi (2016) tarafindan yapılmış ve Türkçe formunun geçerli ve güvenilir olduğu sonucuna varılmıştır.

DTDD-Narsisizm: 4 ayrı çalışmada $(\mathrm{n}=1085)$, Jonason ve Webster (2010) kısaltılmış Karanlık Üçlü Ölçeği geliştirmiş, ölçeğin geçerlik ve güvenirliğini test etmiştir. Ölçek karanlık üçlünün her bir yapısını (narsisizm, Makyavelizm ve psikopati) dörder madde ile ölçmektedir ve ölçeğin psikometrik özellikleri birçok çalışmada kabul edilebilir tespit edilmiştir (Jonason vd., 2011; Lee vd., 2013; Jonason vd. 2013). Ölçek aynı zamanda birçok dile de (Türkçe: Özsoy vd., 2017; Almanca: Küfner vd., 2015; Japonca: Tamura vd., 2015; Lehçe: Czarna vd., 2016) uyarlanmıştır. Buna rağmen ölçek çok kısa olması ve Karanlık Üçlü yapılarının boyutlarını yeterince kapsamaması açısından da eleştirilmektedir (Jones ve Paulhus, 2013; Miller vd., 2012).

SD3-Narsisizm: 4 ayrı çalışmada $(n=1063)$ Jones ve Paulhus (2013) kısaltılmış Karanlık Üçlü Ölçeği geliştirmiş, ölçeğin geçerlik ve güvenirliğini (hem öğrenci örnekleminde hem de genel popülasyon üzerinde) test etmiştir. Ölçek Karanlık Üçlü’nün her bir yapısını dokuzar madde ile ölçmektedir ve ölçeğin psikometrik özellikleri birçok çalışmada kabul edilebilir tespit edilmiştir (örn., Egan, Chan ve Shorter, 2014; Book, Visser ve Volk, 2015) ve farklı dillere uyarlanmıştır (örn., Türkçe: Özsoy vd., 2017; Farsça: Atari ve Chegeni, 2016).

Tek Maddeli Narsisizm Ölçeği (SINS): 11 ayrı çalışmada $(n=2250)$ Konrath, Meier ve Bushman (2014), tek maddeli narsisizm ölçeğinin psikometrik özelliklerini sınamış ve kabul edilebilir düzeyde psikometrik özellikleri olduğu sonucuna varmıştır. Ancak araştırmacılar ölçeği mevcut narsisizm ölçeklerine rakip bir ölçek iddiası ile değil, anket formunun çok uzun olduğu çalışmalarda ve narsisizmin temel değişken olmadığı durumlarda, narsisizmin ölçülebileceği alternatif bir ölçek olarak değerlendirmiştir. van der Linden ve Rosenthal (2015) da çalışmalarında tek maddeli narsisizm ölçeğinin narsisizmin ölçümünde alternatif bir ölçek olarak kullanılabileceği sonucuna varmıştır. Bu bakımdan tek maddeli narsisizm ölçeği kesinlikle mevcut ölçeklere rakip bir ölçek olarak değerlendirilmemelidir. Ölçek Türk kültürüne Özsoy vd., (2017) tarafından uyarlanmış ve psikometrik özelliklerinin kabul edilebilir olduğu sonucuna varılmıştır. Ancak Özsoy vd., (2017) sadece öğrenci örnekleminde ölçeğin psikometrik özelliklerini incelemiştir. Ayrıca tek maddeli ölçeklerin kullanımını cesaretlendirmede dikkatli olunmalıdır (Diamantopoulos vd., 2012). Bu bakımdan daha fazla örneklem büyüklüğünde ve farklı örneklemler üzerinde ölçeğin geçerliliğinin sınanması ve ölçeğin kısitlarının vurgulanmasi gerekmektedir.

\section{Araştırmanın Arka Planı ve Geçerliğin Sınanması}

Belirli bir yapının ölçümü, ağırlıklı olarak o yapıyı içeren boyutları kapsayacak düzeyde gerçekleştirilmektedir. Hatta belirli bir yapı ya da değişkeni teorik olarak söz konusu yapıları temsil 
eden boyutlarla ölçmek de tamamen bir değişkenin ölçülmesini mümkün kılamamaktadır. Çünkü her bir kavram, değişken ya da yapı birbirleri ile ilişkili birçok kavramla ilişkilidir. Örneğin kişilik özellikleri ile ilişkili 15.000'den kavram bulunmaktadır (Barrick ve Mount, 2012). Bununla birlikte özellikle psikoloji çalışmalarında belirli bir yapıyı ölçmek için, kavramın teorik temelleri ile uyuşan boyutlar bazında ölçümler yapılmaktadır. Herhangi bir ölçekte madde sayısının artmasının genel olarak yapıya ilişkin boyutları daha kapsayıcı bir ölçüm ileri sunsa da, belirli bir ölçekteki madde sayısının arttıkça daha geçerli bir ölçüm yapılabilir iddiasını gütmek mümkün değildir. Son dönemlerde birçok uzun formlu ölçeklerin kısaltılması yoluna gidilmektedir (örn., Jonason ve Webster, 2010; Jones ve Paulhus, 2013). Bu kısaltma çalışmalarında bazen belirli yapılar boyutlar bazında değil de tek bir faktör altında ölçülmektedir. Bazen de boyutların sayısı ya da sadece boyutlardaki maddeler azaltılmaktadır (Glover vd., 2012). Özellikle madde sayıs1 100'den fazla olan ölçeklerde katılımcıların ilgisi azalmakta, özensiz katılım oranı ise artabilmektedir (Jonason ve Webster, 2010). Bu sebeple kısaltılmış ölçeklere başvurma eğiliminin arttığı söylenebilir. Ancak sadece katılımcılar açısından daha kolay ve uygulanabilir olması gerekçesi ile ölçeklerin maddelerinin azaltılması hatta "tek maddeye" indirgenmesinin meşru olduğunu ve yöntem bilimsel açıdan kabul edilebilir olduğunu iddia etmek mümkün değildir. Tek maddeli ölçekler sadece belirli bir yapıya dair oldukça sınırlı bir ölçüm yapabilmektedir ve kesinlikle uzun formlu ölçeklere bir rakip olarak değerlendirilmemelidir. Tek maddeli ölçekler belirli bir yapı hakkında genel bir eğilimi ölçme hususunda fikir oluşturma açısından katkı sunabilmektedir.

Narsisizm açısından ele alındığında narsisizmin ölçümünde klinik amaçlı olmayan Narsisistik Kişilik Envanteri çok boyutludur (Raskin ve Hall, 1979; Raskin ve Terry, 1980). Her bir boyut birbirlerinden farklı olsa da, birbirleri ile istatistiki açıdan ilişkilidir. Beş faktör narsisizm envanterinde ise 15 ayrı boyut bazında narsisizm ölçülmektedir. Bu ölçek aynı zamanda kırılgan ve büyüklenmeci narsisizm ayrımlarında da narsisizmi ölçmektedir (Glover vd., 2012). Narsisizmin ölçümünde DTDD ve SD3 ölçekleri boyut bazında ölçümden ziyade genel narsisizmin (subklinik düzeyde) ölçümünü yapmaktadır. Daha önceki çalışmalarda tek maddeli narsisizmin psikometrik özelliklerinin kabul edilebilir düzeyde olduğu tespit edilmiştir. Ölçeğin Türkçe versiyonunun da geçerli olduğu tespit edilmiştir. Ancak tek maddeli ölçeklere şüphe ile yaklaşılmalıdır. Çünkü bu ölçeklerde içsel tutarlılık hesaplaması mümkün değildir (Lucas ve Donnellan, 2011). Özsoy vd., (2017) uyarlama çalışmasında sadece öğrenci örnekleminde ölçeğin psikometrik özelliklerini sınamıştır. Bu bakımdan ölçeğin psikometrik özelliklerinin farklı örneklem gruplanı üzerinde test edilmesinin faydalı olacağı düşünülmektedir.

Tek maddeli narsisizm ölçeğinin geçerliliğinin sınanması için birtakım beklentileri karşılaması gerekmektedir. Buna göre SINS-T’nin yapı geçerliğinin sınanması için nomolojik korelasyonların beklenen düzeyde olması gerekmektedir. Ayırt edici geçerlik açısından çoklu özellikli tekli yöntem ve çoklu özellikli çoklu yöntem korelasyonlarının, tekli-özellikli çoklu yöntem korelasyonlarından daha 
zayıf olması gerekmektedir. Buna göre SINS-T ile Narsisizm ilişkisinin, SINS-T’nin Makyavelizm ve psikopati ile ilişkisinden daha güçlü olması gerekmektedir. Ayrıca SINS-T'nin beş faktör kişilik özelliklerinden dişadönüklükle pozitif (Paulhus ve Williams, 2002; Carter, Campbell ve Muncer, 2013), uyumluluk ile negatif ilişkilenmesi (Paulhus ve Williams, 2002) gerekmektedir. Son olarak kadınların SINS-T'den erkeklere göre daha düşük skor alması gerekmektedir (Czarna vd., 2016; Jonason ve Webster, 2010; Özsoy vd., 2017). SINS-T tek maddeli olduğu için faktör yapısı ve içsel tutarlılık özelliklerine ilişkin beklenti oluşturulamamıştır.

\section{Yöntem}

\section{Çalışma 1}

Örneklem ve Verilerin Toplanması: Araştırmada veriler Sakarya'da faaliyet gösteren bir kamu üniversitesinde görev yapan akademisyenler vasıtasıyla toplanmıştır. Bu kapsamda anket formu katılımcılara online olarak ulaştırılmıştır. Veriler Nisan-Haziran 2018 ayları arasında toplanmıştır. Özensiz ve eksik anket formları çıkarıldıktan sonra toplamda 349 adet anket formu analizler için kullanılmıştır.

\section{Ölçekler}

Narsisizm, Makyavelizm ve Psikopatinin Ölçümü: Narsisizm, Makyavelizm ve psikopati (Karanlık Üçlü), Jonason ve Webster (2010) tarafından geliştirmiş, her bir yapıyı dörder madde ile ölçen 12 maddeli kısaltılmış Karanlık Üçlü Ölçeği’nin (DTDD; Dark Triad Dirty Dozen) Türkçe formu (DTDD-T; Özsoy, Rauthmann, Jonason ve Ardıç, 2017) ile ölçülmüştür. Ölçek 5'li Likert tipi puanlama ile (1-Kesinlikle Katılmıyorum, 5-Kesinlikle Katılıyorum) kullanılmıştır. Ölçeğin Türkçe’ye uyarlaması Özsoy vd. (2017) tarafından yapılmış, psikometrik özelliklerinin kabul edilebilir ve geçerli ve güvenilir olduğu sonucuna ulaşılmıştır.

Tek Maddeli Narsisizm Ölçeği: Ölçek "Ben narsistim ifadesine ne ölçüde katıllyorsunuz? (Not: Narsist kelimesi bencil, kendine odakl ve kendini beğenmiş anlamına gelmektedir" ifadesinden oluşmaktadır (Konrath, Meier, ve Bushman 2014). Ölçeğin Türkçeye çevrisi ve uyarlaması Özsoy vd., (2017) tarafından yapılmıştır ve ölçek 7'li Likert tipinde (1-Beni ifade etmiyor; 7-Tam olarak beni ifade ediyor) geliştirilmiş ve uyarlanmıştır dolayısıyla bu çalışmada da aynı formatta kullanılmıştır.

Katılımcılar: Araştırmaya toplamda 349 akademisyen katılmıştır. Katılımcıların \% 54.7'si erkek ve \% 45.3'ü kadındır. Katılımcıların \% 37.5'i Arş.Gör, \% 8'i Öğretim Görevlisi, \% 1.4’i Uzman/Okutman, \% 32.1'i Dr. Öğretim Üyesi, \% 12.3'i Doçent ve \% 8.6's1 Profesördür. Akademisyenlerin \% 65.6'sı sosyal bilimler, \% 22.3'ü fen bilimleri, \% 6.3'ü sağlık bilimleri ve \% 5.4'ü eğitim bilimleri alanlarında çalışmaktadır. Akademisyenlerin en son mezun oldukları eğitim düzeyine ilişkin dağ 11 lı ise şu şekildedir; \% 63'ü doktora, \% 30,7'si yüksek lisans ve \% 6,3'ü lisans mezunudur. Akademisyenlerin yaş ortalaması 38.16 (Standart sapma $=10.40)$ ve ortalama çalışma süresi 11.07 ylldır (standart sapma $=9.80$ ). 


\section{Bulgular}

Tanımlayıcı istatistikler, içsel tutarlılık bulguları ve cinsiyet farklılıklarının testine ilişkin bulgular (Bağımsız Örneklemler T Testi ve Hedges' g Testi) Tablo 1'de, yapı geçerliliği bulguları Tablo 2'de sunulmuştur.

Tablo 1. Tanımlayıcı İstatistikler, içsel Tutarlıık, T Testi ve Hedges g Testi Bulguları

\begin{tabular}{lcccccc}
\hline & & \multicolumn{5}{c}{ O(SS) } \\
\cline { 3 - 5 } Değişkenler & $\alpha$ & Total & Erkek & Kadın & $t$ & $\mathbf{g}$ \\
\hline SINS-T & - & $2.16(1.33)$ & $2.34(1.43)$ & $1.95(1.17)$ & $2.75^{* *}$ & 0.30 \\
Narsisizm & .82 & $2.42(0.93)$ & $2.53(0.95)$ & $2.29(0.88)$ & $2.37^{* *}$ & 0.26 \\
Makyavelizm & .81 & $1.58(0.66)$ & $1.67(0.72)$ & $1.46(0.56)$ & $3.02^{* *}$ & 0.32 \\
Psikopati & .72 & $1.68(0.63)$ & $1.80(0.67)$ & $1.51(0.55)$ & $4.43^{* * *}$ & 0.46
\end{tabular}

Not. $\mathrm{n}=349 . \mathrm{O}=$ Ortalama, SS = Standart Sapma, $\mathrm{a}=$ Cronbach's $\mathrm{a}, \mathrm{g}=$ Hedges' $\mathrm{g} ;{ }^{*} \mathrm{p}<.05,{ }^{* *} \mathrm{p}<.01,{ }^{* * *} \mathrm{p}$ $<.001$

Tablo 1'de görülüğü üzere araştırma kapsamında kullanılan ölçeklerin içsel tutarlılık değerleri kabul edilebilir düzeydedir (en düşük $\alpha$ değeri $=0.72$ ). Karanlık Üçlü bileşenlerinden en yüksek değeri narsisizm almıştır ancak genel olarak tüm bileşenlerin ortalama değerleri (SINS-T dâhil) oldukça düşüktür. Bağımsız Örneklemler T testinde erkekler hem SINS-T hem de Karanlık Üçlü bileşenleri bağlamında kadınlardan daha yüksek skor almıştır. Farklılıkların incelenmesinde T Testine ek olarak Hedge $g$ testine de başvurulmuştur. Psikopati haricinde genel olarak düşük bir etki büyüklüğü ile erkekler kadınlardan tüm bileşenler dâhil yüksek skor almıştır. Bu bulgu kısmen de olsa SINS-T’nin psikometrik özelliklerini desteklemektedir.

Tablo 2. Yapı Geçerliği Bulguları

\begin{tabular}{|c|c|c|c|c|c|c|c|c|c|c|}
\hline \multirow[t]{2}{*}{ Değiş̧kenler } & \multicolumn{4}{|c|}{ Korelasyon Analizi } & \multicolumn{6}{|c|}{ Z Testi } \\
\hline & 1 & 2 & 3 & 4 & $M$ & $z$ & $p$ & $P$ & $z$ & $p$ \\
\hline 1.SINS-T & - & & & & $.43^{* * *}$ & & & $.36 * * *$ & & \\
\hline 2.Narsisizm (N) & $.52 * * *$ & - & & & $.49 * * *$ & ${ }^{-1.32}$ & .10 & $.38 * * *$ & -0.41 & 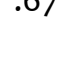 \\
\hline 3.Makyavelizm (M) & $.43^{* * *}$ & $.49 * * *$ & - & & & & & & & \\
\hline 4.Psikopati (P) & $.36^{* * *}$ & $.38 * * *$ & $.52^{* * *}$ & - & & & & & & \\
\hline
\end{tabular}

Yap1 geçerliliği testi için SINS-T, narsisizm, Makyavelizm ve psikopati arasındaki ilişkiler incelenmiştir (Tablo 2). Yakınsak geçerliği destekleyecek nitelikte SINS-T ve narsisizm orta düzeyde ilişkilenmiş̧ir. SINS-T’nin narsisizm ile ilişkisi Makyavelizm ve psikopatiden daha yüksektir. Bu bulgu SINS-T'nin ayırt edici geçerliğini desteklemektedir. Ek olarak SINS-T'nin ve narsisizmin Makyavelizm ve psikopati ile ilişkileri Steiger'ın (1980) geliştirdiği z testi formülü ile karşılaştırılmıştır. $\mathrm{Bu}$ test korelasyon katsayılarının anlamlı farklılık gösterip göstermediğini test 
etmektedir. Görüldügü üzere SINS-T’nin Makyavelizm ve psikopati ile ilişkisi, narsisizmin Makyavelizm ve psikopati ile ilişkisinden farklı değildir $(\mathrm{p}<0.05)$. Bu bulgu da SINS-T'nin psikometrik özelliklerini desteklemektedir. Son olarak narsisizm, Makyavelizm ve psikopati yapılarının birbirleri ile ilişkisine yönelik elde edilen etki büyüklükleri daha önceki çalışmalarla benzer doğrultuda tespit edilmiştir.

\section{Çalışma 2}

Örneklem ve Verilerin Toplanması: Araştırmada veriler Sakarya'da faaliyet gösteren çeşitli özel ve kamu sektör örgütlerinde çalışan, iş görenlerin katılımıyla elde edilmiştir. Araştırmada veriler el ile dağıtım yolu ile katılımcılara ulaştırılmıştır. Veriler Ocak-Nisan 2018 aralığında toplanmıştır. Eksik ve özensiz anket formları elimine edildikten sonra toplamda 236 çalışan araştırmaya katılmıştır.

\section{Ölçekler}

Beş Faktör Kişilik Envanteri: Benet-Martínez ve John (1998) tarafindan geliştirilen 44 maddeli beş faktör kişilik ölçeğinin (Büyük Beşli: Big Five), Türkçe formu (Sümer ve Sümer, 2005), 5'li Likert tipinde (1 Kesinlikle Katılmıyorum-5: Kesinlikle Katılıyorum) kullanılmıştır. Deneyime açıklık 10 madde, sorumluluk 9 madde, dışadönüklük 8 madde, uyumluluk 9 madde ve nevrotiklik 8 maddeden oluşmaktadır. Ölçekte yer alan ters kodlu maddeler, boyut skorları hesaplanmadan önce yeniden kodlanmıştır.

Narsistik kişilik Envanteri (Narcissistic Personality Inventroy-16: NPI-16): Ames, Rose ve Anderson (2006) tarafından 16 maddeye indirgenmiş, Kısaltılmış Narsisizm Envanterinin Türkçe formu (Atay, 2009) kullanılmıştır. Her bir madde iki ayrı madde çiftinden oluşmaktadır. Bu maddelerden biri narsisizmi temsil eden, diğeri ise narsisizmi temsil etmeyen ifadelerden oluşmaktadır, katılımcılardan bu madde çiftlerinden birini seçmeleri istenmiştir. Narsisizmi temsil eden maddelerin toplamı ile narsisizm skoru elde edilmiştir.

Tek Maddeli Narsisizm Ölçeği: Çalışma 1'de açıklanmıştır.

Katılımcılar: Araştırmaya toplamda 236 çalışan katılıışır. Katılımcıların \% 52.5'i kadın, \% 58.5'i evli, \% 61.4'ü özel sektör çalışanıdır. \% 8.5'i lise öncesi, \% 25.4'ü lise, \% 8.9'u ön lisans, $\% 45.1$ 'i lisans ve \% 10.2'si yüksek lisans ve üzeri eğitim düzeyine sahiptir. Katılımcıların yaş ortalaması 34.42 (standart sapma 9.77) ve ortalama çalışma süresi 12.71 yıldır (standart sapma = 10.06).

\section{Bulgular}

Tanımlayıcı istatistikler, içsel tutarlılık bulguları ve cinsiyet farklılıklarının testine ilişkin bulgular (Bağımsız Örneklemler T Testi ve Hedges $g$ Testi) Tablo 3’te, yapı geçerliliği bulguları Tablo 4'te sunulmuştur. 
Tablo 3. Tanımlayıcı İstatistikler, icçsel Tutarlılık, T Testi ve Hedges g Testi Bulguları

\begin{tabular}{|c|c|c|c|c|c|c|}
\hline \multirow[b]{2}{*}{ Değișkenler } & \multirow[b]{2}{*}{$\alpha$} & \multicolumn{3}{|c|}{$O(S S)$} & \multirow[b]{2}{*}{$t$} & \multirow[b]{2}{*}{ g } \\
\hline & & Total & Erkek & Kadın & & \\
\hline SINS-T & - & $2.32(1.61)$ & $2.65(1.30)$ & $2.06(1.35)$ & $2.81 * *$ & 0.60 \\
\hline NPI-16 & .71 & $6.17(3.36)$ & $6.65(3.52)$ & $5.76(3.20)$ & $2.04^{*}$ & 0.27 \\
\hline Deneyime Açıklık & .80 & $3.54(0.71)$ & & & & \\
\hline Sorumluluk & .75 & $3.32(0.64)$ & & & & \\
\hline Dışadönüklük & .83 & $3.35(0.82)$ & & & & \\
\hline Uyumluluk & .71 & $3.74(0.63)$ & & & & \\
\hline Nevrotiklik & .77 & $3.18(0.83)$ & & & & \\
\hline
\end{tabular}

Not. $\mathrm{n}=236 . \mathrm{O}=$ Ortalama, SS = Standart Sapma, $\alpha=$ Cronbach's $a, g=$ Hedges' $g ; * \mathrm{p}<.05, * * \mathrm{p}<.01, * * * \mathrm{p}$ $<.001$

Tablo 3’te görülügü üzere araştırma kapsamında kullanılan ölçeklerin içsel tutarlılık değerleri kabul edilebilir düzeydedir (en düşük $\alpha$ değeri $=0.71$ ). Hem SINS-T hem de NPI-16 ölçekleri için narsisizm düşük düzeyde tespit edilmiştir. Cinsiyet farkl11ıkları Bağımsız Örneklemler T Testi ve Hedges $g$ Testi ile incelenmiştir. Tablo 3'te görüldüğü üzere erkekler kadınlardan hem SINS-T'de hem de NPI-16'da daha yüksek skor almıştır. Bu bulgu SINS-T’nin psikometrik özelliklerini desteklemektedir.

Tablo 4. Yapı Geçerliği Bulguları

\begin{tabular}{|c|c|c|c|c|}
\hline \multirow[t]{2}{*}{ Değişkenler } & \multicolumn{2}{|c|}{ Korelasyon Analizi } & \multicolumn{2}{|c|}{ Z Testi } \\
\hline & SINS-T & NPI-16 & $z$ & $P$ \\
\hline NPI-16 & $.51 * * *$ & 1 & & \\
\hline Deneyime Açıklık & $.15^{*}$ & $.25^{* * *}$ & -1.59 & .11 \\
\hline Sorumluluk & -.08 & .04 & -1.86 & .06 \\
\hline Dışadönüklük & $.20 * *$ & $.29 * * *$ & -1.45 & .15 \\
\hline Uyumluluk & $-.28 * * *$ & $-.17^{*}$ & 1.77 & .08 \\
\hline Nevrotiklik & .11 & .02 & 1.39 & .16 \\
\hline
\end{tabular}

Yap1 geçerliliği testi için SINS-T’nin, narsisizm (NPI-16) ve Beş Faktör kişilik özellikleri ile ilişkisi incelenmiştir. Buna göre ilk olarak SINS-T ve NPI-16 arasında orta düzeyde bir ilişki elde edilmiştir. Bu bulgu SINS-T’nin yakınsak geçerliğini desteklemektedir. Nomolojik ağlar yaklaşımına göre narsisizmin uyumluluk ile negatif, dışadönüklükle de pozitif ilişkilenmesi gerekmektedir. Görüldüğü üzere hem SINS-T hem de NPI-16 uyumluluk ile negatif, dışadönüklükle de pozitif ilişkilenmiştir. Bu bulgu SINS-T’nin yakınsak (dışadönüklük açısından) ve ayırt edici (uyumluluk açısından) geçerliliğini destekler niteliktedir. Beş faktör kişilik özelliklerinin diğer bileşenlerine ilişkin 
net bir beklenti belirlemek güçtür. Çünkü daha önceki çalışmalarda beş faktör kişilik özellikleri ve narsisizm arasında elde edilen ilişkiler birbirleri ile tutarlı değildir. Son olarak SINS-T ve NPI-16'nın beş faktör kişilik özellikleri ile ilişkilerinde farklılık olup olmadığını test etmek için z testine başvurulmuştur. Tablo 4'de görüldüğü üzere SINS-T ve NPI-16'nın beş faktör kişilik özellikleri ile korelasyon katsayıları istatistiki açıdan farklı1ıklar sergilememiştir.

\section{Tartışma ve Eleştiriler}

Çalışma 1: Çalışma 1'de kullanılan ölçeklerin içsel tutarlılık değerleri kabul edilebilir düzeyde tespit edilmiştir. Beklenildiği üzere daha önceki çalışmalarla uyumlu bir şekilde hem SINS-T hem de Karanlık Üçlü bileşenleri erkeklerde daha yüksek düzeyde tespit edilmiştir (Bağımsız örneklemler T Testi ve Hedges g Testi Bulguları) (Jonason ve Webster, 2010; Özsoy vd., 2017). Bu bulgular SINST’nin psikometrik özelliklerini desteklemektedir. Yap1 geçerliliği testi için uygulanan korelasyon analizinde ise SINS-T narsisizm ile orta düzeyde ilişkilenmiştir. Bu bulgu ölçeğin yakınsak geçerliğini desteklemektedir. SINS-T'nin ayırt edici geçerliğini sınamak için; SINS-T’nin Narsisizm ile ilişkisi, Makyavelizm ve Psikopati ile ilişkisi ile karşılaştırılmıştır. SINS-T'nin en yüksek düzeyde ilişkilendiği değişken narsisizm olmuştur. SINS-T Makyavelizm ve psikopati ile kıyasla Narsisizm ile daha yüksek bir korelasyon katsayısı ile ilişkilenmiştir. Bu bulgu ölçeğin ayırt edici geçerliğini desteklemektedir. Son olarak SINS-T'nin Makyavelizm ve psikopati ile ilişkisi ile narsisizmin Makyavelizm ve psikopati ile ilişkisi z testinde karşılaştırılmıştır. Elde edilen bulgulara göre SINST'nin Makyavelizm ve psikopati ile ilişkisi, narsisizmin Makyavelizm ve psikopati ile ilişkisinden farklı değildir. Yani SINS-T ve Narsisizm, Makyavelizm ve psikopati ile benzer korelasyon katsayısı ile ilişkilenmektedir. Bu bulgu SINS-T’nin psikometrik özelliklerini desteklemektedir.

Çalışma 2: Çalışma 2'de kullanılan tüm ölçeklerin içsel tutarlılık değerleri kabul edilebilir düzeyde tespit edilmiştir. Beklenildiği üzere Bağımsız Örneklemler T Testi ve Hedges g Testi Bulgularına göre; SINS-T ve NPI-16 erkeklerde daha yüksek düzeyde tespit edilmiştir. Bu bulgu daha önceki çalışmalarla uyumludur (Czarna vd., 2016) ve SINS-T’nin psikometrik özelliklerini desteklemektedir. Yapı geçerliliği testi için uygulanan korelasyon analizinde ise SINS-T narsisizm (NPI-16) ile orta düzeyde ilişkilenmiştir. Bu bulgu ölçeğin yakınsak geçerliğini desteklemektedir. Yine geçerlik beklentilerinde vurgulandığı üzere narsisizm daha önceki çalışmalarda (Ardiç ve Özsoy, 2016; Paulhus ve Williams, 2002; Carter, Campbell ve Muncer, 2013) ağırlıklı olarak dışadönükle pozitif, uyumlulukla da negatif ilişkilenmiştir. Dolayısı ile SINS-T'nin geçerliğinin desteklenmesi için bu çalışmada da SINS-T açısından benzer sonuçlar elde edilmelidir. Nitekim SINS-T ile; dışadönüklük arasında pozitif uyumluluk arasında negatif ilişki elde edilmiştir. Ayrıca SINS-T ile NPI-16'nın beş faktör kişilik özellikleri ile ilişkisine yönelik elde edilen korelasyon katsayıları Steiger'ın (1980) geliştirdiği formül ile kıyaslanmıştır ve SINS-T ile NPI-16'nın beş faktör kişilik 
özellikleri ile korelasyon katsayıları farklılaşmamıştır. Bu bulgu da SINS-T'nin psikometrik özelliklerini destekler niteliktedir.

Genel değerlendirme ve eleştiriler: Tartışma 1 ve Tartışma 2'de vurgulandığı üzere SINST’nin psikometrik özellikleri büyük ölçüde kabul edilebilir düzeyde tespit edilmiştir. Ancak bu bulgu kesinlikle SINS-T'nin NPI-16 ya da DTDD-Narsisizm kadar narsisizmi ölçebileceği anlamına gelmemektedir. Öncelikle tek maddeli ölçekler üzerinde kritik eleştiriler bulunmaktadır. Bu eleştiriler yöntemsel açıdan tek maddeli narsisizm için de geçerlidir. Bu kapsamda Diamantopoulos vd. (2012) çalışmasında tek maddeli ölçeklerin çok boyutlu ölçeklere tercih edilmesindeki kısıt ve eleştirileri üç boyut altında incelemiştir. Buna göre ilk olarak tek maddeli ölçekler her zaman çok boyutlu ölçeklerle benzer psikometrik özellikler sergileyememektedir. İkinci husus eğer bir araştırmada bir yapı tek madde ile ölçülüyor ve devamında başka bir yapı tek madde ile ölçülüyorsa burada "carry-over effects" yani katılımcıların birbirini takip eden maddelerden etkilenme ihtimali artmaktadır. Bu durum ise ölçeğin geçerliğini olumsuz etkilemektedir. Üçüncü husus ise korelasyon katsayıları karşılaştırılarak ölçeğin psikometrik özelliklerinin incelenmesinde aynı örneklem üzerinde karşılaştırma yapılmasıdır. Bunun yerine farklı örneklemler üzerinde korelasyon katsayılarının karşılaştırılması daha sağlıkı sonuçlar elde edilmesine katkı sunmaktadır. Tek maddeli ölçeklerin bir diğer önemli kısıtı ise güvenilirliklerinin hesaplanmasının güçlüğüdür. Buna göre güvenilirliğin en yaygın hesaplandığı Cronbach Alfa içsel tutarlılık testi tek maddeli ölçeklerin içsel tutarlılık değeri hesaplanamamaktadır (Lucas ve Donnellan, 2011). Bu kısıt tek maddeli narsisizm ölçeği için de geçerlidir. Ek olarak tek maddeli ölçekler kapsamı dar olan boyutlandırılmaya ihtiyaç duyulmayan kavramların ölçümünde daha uygun olarak değerlendirilmektedir. Buna karşıllk kişilik gibi kapsamı geniş ve çok boyutlu kavramların tek madde ile ölçülmesi eleştirilmektedir (Wanous, Reichers ve Hudy, 1997). Narsisizm de bir kişilik özelliği olduğu için tek madde ile ölçülmesi zorlaşmaktadır.

Tek maddeli ölçeklerin kısıtları ve eleştirileri hususunda Diamantopoulos vd.'nin (2012) belirtiği noktalara ek olarak Sauro, (2018) da birtakım eleştiriler ileri sürmüştür. Bu hususta ilk olarak karmaşık teorik kavramların tek madde ile ölçülüp, bu kavramın ya da yapının içeriğini tam olarak yansıtma ihtimali düşüktür, bu durum ise düşük içerik geçerliğine neden olmaktadır (McIver ve Carmines,1981: 15; akt., Sauro, 2018). İkinci husus tek maddeli ölçeklerde örneğin 5'li Likert tipi puanlama yöntemi kullanıldığında, sadece 5 ayrı dereceleme söz konusudur. Buna karşılık 10’lu puanlama yapıldığında, 50 ayrı dereceleme söz konusudur ki bu da ayırt ediciliği artırmaktadır. Bu durum tek maddeli ölçeklerin hassasiyet düzeyini azaltmaktadır (Sauro, 2018).

Narsisizm klinik (APA, 2013) ve subklinik düzeyde (Özsoy ve Ardiç, 2017) incelenen, karmaşık ve çok boyutlu bir yapıdır (Glover vd., 2012). Buna göre kırılgan narsisizm, büyüklenmeci narsisizm, patolojik narsisizm, normal narsisizm, hipersensitif narsisizm ve toplumsal narsisizm çok çeşitli sınıflandırmalar kapsamında incelenmektedir. Ek olarak narsisizm farklı boyutlar kapsamında (örn., liderlik, otorite, teşhircilik, hak iddia etme, manipülatiflik, kendine hayranlık) (Glover vd., 2012; 
Raskin ve Terry, 1979) da ölçülmektedir. Dolayısı ile tek bir madde ile söz konusu sınıflandırma ya da boyutlar bazında bir çıkarım yapmak mümkün değildir. Bu bakımdan kesinlikle tek maddeli narsisizm ölçeği mevcut ölçeklere rakip olarak değerlendirilmemelidir. Ayrıca tek maddeli narsisizm ölçeği özellikle kırılgan narsisizm, patolojik narsisizm, hipersensitif narsisizm ve toplumsal narsisizm gibi sınıflandırmaları ölçmede asla yeterli değildir. Çünkü söz konusu narsisizm ayrımları büyüklenmeci narsisizm ile düşük düzeyde ilişkildir. Tek maddeli narsisizm ölçeği ise ağırlıklı olarak büyüklenmeci narsisizme daha yakın bir içeriğe sahiptir. Ancak yine de bu yapıyı1 içerik olarak kapsaması güçtür. $\mathrm{Bu}$ durum ölçeğin kullanılabilirlik alanını kısıtlamaktadır. Bu bakımdan mümkün olduğunca tek maddeli narsisizm ölçeğine başvurulması önerilmemektedir. Tek maddeli narsisizm ölçeği, kişideki subklinik narsisizm düzeyi hakkında fikir verebilecek düzeyde bir eğilimi yansıtabilir ve eğer narsisizm bir çalışmada ana değişken değilse, araştırmada kullanılan anket formu çok uzunsa tercih edilebilecek bir ölçektir. Ayrıca herhangi bir yapının bireysel farklılıklar bağlamında öncüllerine ilişkin araştırmalar yürütülüyorsa tek maddeli narsisizm ölçeği destekleyici nitelikte kullanılabilir. Aksi durumlarda 4 (Miller vd., 2012) ve 9 maddeli ölçekler bile henüz yeterli desteği alamamışken tek maddeli narsisizmin kullanımına ilişkin cesaretlendirici önerilerde bulunmak sakıncalıdır.

Araştırmanın Kısıtları: Araştırmada beş faktör kişilik özellikleri ölçeği haricinde kullanılan diğer ölçekler kısaltılmış formlu ölçeklerdir. Dolayısı ile her ne kadar farklı örneklemler üzerinden farklı ölçüt geçerlik değişkenleri ile SINS-T'nin psikometrik özellikleri sınansa da, mevcut bulgular halen iddialı çıkarımlar yapabilmek için yeterli değildir. Ayrıca SINS-T tek maddeli olduğu için SINST’nin güvenilirliğini içsel tutarlılık testi ile ölçmek mümkün değildir. Bu durumda sadece test-yeniden test yöntemi ile ölçeğin güvenirliği incelenebilmektedir. Ancak bu çalışmada söz konusu analize yer verilmemiştir.

Gelecek Araştırma Önerileri: Öncelikle bundan sonraki araştırmalarda tek maddeli narsisizm ölçeğinin güvenirliğini sınamak için test-yeniden test yönteminde başvurulmalıdır. Bundan sonra yapılacak geçerlik sınamalarında tek maddeli narsisizmin tercihen heterojen ve çok sayıda katılımcı ile narsisizm sınıflandırmalarına yönelik geçerliği test edilmiş ölçeklerle birlikte sınanması önerilmektedir. Çünkü her ne kadar tek maddeli narsisizm ölçeğinin teorik olarak kırılgan narsisizm, patolojik narsisizm, hipersensitif narsisizm ve toplumsal narsisizm gibi sınıflandırmalarla uyuşma düzeyi düşük olsa da hangi sınıflandırmaya daha yakın olduğu yönünde çıkarım yapılabilecek yeterli çalışma bulunmamaktadır. Böylelikle tek maddeli narsisizm ölçeğinin hangi sınıflandırmaya daha yakın bir ölçüm yaptığı ve hangi sınıflandırmalarla uyuşmadığı yönünde ek bulgular elde edilebilir. Aksi takdirde karmaşık ve çok boyutlu bir yapının hangi yönünü daha iyi açıkladığı bilinmeyen bir ölçeğin kullanım alanı kısıtlanmaktadır.

Sonuç olarak birçok kısıt dâhilinde yürütülen bu araştırmada her ne kadar SINS-T'nin psikometrik özellikleri belli ölçüde desteklense de SINS-T’nin psikometrik özelliklerine dair kısıtlar giderilmeden ölçeğin kullanılmasına şüphe ile yaklaşılmaktadır. Yukarıda açıklandığı üzere sadece 
narsisizm değil, genel olarak çoğu tek maddeli ölçek birçok araştırmacı tarafindan eleştiri konusudur. Narsisizm özelinde ele alındığında ise narsisizmin farklı sınıflandırma ve boyutlar bazında değerlendirilen bir yap1 olması, tek maddeli narsisizm ölçeğinin en azından hangi sınıflandırmaya daha yakın bir ölçüm yaptığını kısıtlamaktadır. Dolayısı ile daha kapsayıcı çıkarımlarda bulunabilmek için özellikle gelecek araştırma önerilerinde vurgulanan hususlarda ek çalışmalara ihtiyaç duyulmaktadir. 


\section{Kaynakça}

Amerikan Psikiyatri Birliği, APA, (2013). Diagnostic and statistical manual of mental disorders (5. Baskı). Washington, DC: Londra, İngiltere. American Psychiatric Association.

Ames, Daniel R., Rose, Paul., ve Anderson, Cameron, P. (2006). The NPI-16 as a short measure of narcissism. Journal of Research in Personality, 40, 440-450.

Ardiç, Kadir., ve Özsoy, Emrah. (2016). Examining the relationship between the dark triad traits and bigfive personality dimensions. Proceedings of thefifth European academic research conference on global business, economics,finance and banking (EAR16TurkeyConference), Istanbul-Turkey.

Atari, Mohammad., ve Chegeni, Razieh. (2016). Assessment of dark personalities in Iran: Psychometric evaluation of the Farsi translation of the Short Dark Triad (SD3-F). Personality and Individual Differences, 102, $111-117$.

Atay, Salim. (2009). Narsistik Kişilik Envanteri'nin Türkçe'ye standardizasyonu. Gazi Üniversitesi İktisadi ve İdari Bilimler Fakültesi Dergisi, 11, 181-196.

Barrick, Murray. R., ve Mount, Michael. K. (2012). Nature and use of personality in selection. In N. Schmitt (Ed.), The Oxford handbook of personnel assessment and selection (pp.225-251). New York, NY: Oxford University Press.

Blair, Carrie. A., Hoffman, Brian. J., ve Helland, Katherine. R. (2008). Narcissism in organizations: A multisource appraisal reflects different perspectives. Human Performance, 21, 254-276.

Book, Angela., Visser, Beth. A., ve Volk, Anthony, A. (2015). Unpacking "evil": Claiming the core of the Dark Triad. Personality and Individual Differences, 73, 29-38.

Brown, Ryan. P., Budzek, Karolyn., ve Tamborski, A. Micheal. (2009). On the meaning and measure of narcissism. Personality and Social Psychology Bulletin. 35, 951-964.

Campbell, W. Keith., Hoffman, Brian. J., Campbell, Stacy. M., ve Marchisio, Gaia. (2010). Narcissism in organizational contexts. Human resource management review, 21, 268-284.

Chatterjee, Arijit., ve Hambrick, Donald. (2007). It's all about me: Narcissistic CEOs and their effects on company strategy and performance. Administrative Science Quarterly, 52, 351-386.

Czarna, Anna. Z., Jonason, Peter. Karl., Dufner, Michael., ve Kossowska, Malgorzata. (2016). The Dirty Dozen Scale: validation of a Polish version and extension of the nomological net. Frontiers in Psychology: Quantitative Psychology and Measurement, 7, 445.

Diamantopoulos, Adamantios., Sarstedt, Marko., Fuchs, Christoph., Wilczynski, Petra., ve Kaiser, Sebastian. (2012). Guidelines for choosing between multi-item and single-item scales for construct measurement: a predictive validity perspective. Journal of the Academy of Marketing Science, 40, 434-449.

Egan, Vincent., Chan, Stephanie., ve Shorter, Gillian.W. (2014). The Dark Triad, happiness and subjective well-being. Personality and Individual Differences, 67, 17-22.

Ekşi, Füsun. (2016). The short form of the Five-Factor Narcissism Inventory: Psychometric equivalence of the Turkish version. Educational Sciences: Theory ve Practice, 16, 1081-1096.

Emmons, Robert. A. (1984). Factor analysis and construct validity of the Narcissistic Personality Inventory. Journal of Personality Assessment, 48, 291-300.

Emmons, Robert. A. (1987). Narcissism: Theory and measurement. Journal of Personality and Social Psychology, 52, 11-17.

Gebauer, Jochen. E., Sedikides, Costantine., Verplanken, Bas., ve Maio, Gregory, R. (2012). Communal narcissism. Journal of Personality and Social Psychology, 103, 854-878.

Gentile, Brittany., Miller, Joshua. D., Hoffman, Brian. J., Reidy, Dennis. E., Zeichner, Amos., ve Campbell, W. Keith. (2013). A test of two brief measures of grandiose narcissism: The Narcissistic Personality Inventory-13 and the Narcissistic Personality Inventory-16. Psychological Assessment, 4, 1120-36.

Glover, Natalie., Miller, Joshua. D., Lynam, Donald. R., Crego, Chiristina., ve Widiger, Thomas. A. (2012). The Five-Factor Narcissism Inventory: A five-factor measure of narcissistic personality traits. Journal of Personality Assessment, 94, 500-512. 
Grijalva, Emily., ve Harms, Peter, D. (2014). Narcissism: An integrative synthesis and dominance complementarity model. Academy of Management Perspectives, 28, 108-127.

Hendin, Holly. M., ve Cheek, Jonathon. M. (1997). Assessing hypersensitive narcissism: A reexamination of Murray's Narcissism Scale. Journal of Research in Personality, 31, 588-599.

Jonason, Peter, Karl., ve Webster, Gregory, D. (2010). The Dirty Dozen: A concise measure of the Dark Triad. Psychological Assessment, 22, 420-432.

Jonason, Peter, Karl., Kaufman, Scot. Barry., Webster, Gregory. D., ve Geher, Glenn. (2013). What lies beneath the Dark Triad Dirty Dozen: Varied relations with the Big Five. Individual Differences Research, 11, 81-90.

Jonason, Peter, Karl., Valentine, Katherine. A., Li, Norman. P., ve Harbeson, Carmelita. L. (2011). Mateselection and the Dark Triad: facilitating a short-term mating strategy and creating a volatile environment. Personality and Individual Differences, 51, 759-763.

Jones, Daniel. N., ve Paulhus, Delroy, L. (2013). Introducing the Short Dark Triad (SD3-T3): A Brief Measure of Dark Personality Traits. Assessment, 21, 28-41.

Kızıltan, Hakan. (2000). Narcissistic Personality Inventory (NPI) ölçeğinin Türkçe formu dil eşdeğerliliği, güvenirlik ve geçerlilik çalışmaları. (Yüksek Lisans Tezi). İstanbul Üniversitesi Sosyal Bilimler Enstitüsü. İstanbul.

Konrath, Sara, H. (2008). Egos inflating over time: Rising narcissism and it implications for self-construal, cognitive style, and behavior. Dissertation Abstracts International B: The Sciences and Engineering, 7024 (Erişim Adresi;https://deepblue.lib.umich.edu/bitstream/handle/2027.42/57606/skonrath_2.pdf?sequence=2)

Konrath, Sara., Brian, P. Meier., ve Bushman, Brad. J. (2014). Development and validation of the Single Item Narcissism Scale (SINS). PLoS ONE, 9, 8.

Kubarych, Thomas. S., Deary, Ian. J., ve Austin, Elizabeth, J. (2004). The Narcissistic Personality Inventory: Factor structure in a non-clinical sample. Personality and Individual Differences, 36, 857-872.

Küfner, Albrecht, C, P., Dufner, Michael., ve Back, Mitja. D. (2015). Das Dreckige Dutzend und die Niederträchtigen Neun Kurzskalen zur Erfassung von Narzissmus, Machiavellismus und Psychopathie. Diagnostica, 61, 76-91.

Lee, Kibeom., Ashton, Michael. C., Wiltshire, Jocelyn., Bourdage, Joshua. S., Visser, Beth. A., ve Gallucci, Alissa. (2013). Sex, power, and money: Prediction from the Dark Triad and Honesty-Humility. European Journal of Personality, 27, 169-184.

Lucas, Richard. E., ve Donnellan, M. Brent. (2011). Estimating the reliability of single-item life satisfaction measures: Results from four national panel studies. Social Indicators Research, 105, 323-331.

McIver, John. P., ve Carmines, Edward, G. (1981). Unidimen-sional Scaling. Sage, Beverly Hills, CA.

Miller, Joshua. D., Few, Lauren. R., Seibert, Lauren. Alana., Watts, Ashley., Zeichner, Amos., ve Lynam, Donald, R. (2012). An examination of the Dirty Dozen measure of psychopathy: a cautionary tale about the costs of brief measures. Psychological Assessment, 24, 1048-1053.

Özsoy, Emrah. (2018). Dark Triad and counterproductive work behaviors: which of the Dark Triad traits is more malevolent? Journal of Business Research-Turk, 10, 742-756.

Özsoy, Emrah. (2019). Yöneticilerin karanlık kişilik özelliklerinin çalışanların tükenmişlik düzeylerine etkisi. Selçuk Üniversitesi Sosyal Bilimler Meslek Yüksekokulu Dergisi, 22, 194-203.

Özsoy, Emrah., Rauthmann, John. F., Jonason, Peter. Karl., ve Ardıç, Kadir. (2017). Reliability and validity of Turkish version of Dark Triad Dirty Dozen (DTDD-T), Short Dark Triad (SD3-T) and Single Item Narcissism Scale (SINS-T). Personality and Individual Differences, 117, 11-14.

Özsoy, Emrah., ve Ardiç, Kadir. (2017). Karanlik Üçlü'nün (Narsisizm, Makyavelizm ve Psikopati) İş Tatminine Etkisinin İncelenmesi. Yönetim ve Ekonomi, 24, 391-406.

Pincus, Aaron. L., Ansell, Emily. B., Pimentel, Claudia. A., Cain, Nicole. M., Wright, Aidan., ve Levy, Kenneth. N. (2009). Initial construction and validation of the Pathological Narcissism Inventory. Psychological Assessment, 21, 365-379. 
Raskin, Robert., ve Terry, Howard. (1988). A Principal-Components Analysis of the Narcissistic Personality Inventory and Further Evidence of Its Construct Validity. Journal of Personality and Social Psychology, 54, 890-902.

Raskin, Robert., ve Hall, Calvin, S. (1979). A Narcissistic Personality Inventory. Psychological Reports, 40, 590.

Rauthmann, John. F., ve Kolar, Gerald. (2012). How “dark" are the Dark Triad traits? Examining the darkness of narcissism, Machiavellianism, and psychopathy. Personality and Individual Differences, 53, 884889.

Sackett, Paul. R., ve Larson, James. R. (1990). Research strategies and tactics in I/O psychology. In M. D. Dunnette, P. L. Ackerman, L. M. Hough, \& H. C. Triandis (Eds.), Handbook of industrial and organizational psychology Vol 1 (pp. 419-489). Palo Alto: Consulting Psychologists Press.

Sauro, Jeff. (2018). Is a single item enough to measure a construct (Erişim adresi: https://measuringu.com/single-multi-items/)

Steiger, James. H. (1980). Tests for comparing elements of a correlation matrix. Psychological Bulletin, 87, 245-251.

Tamura, Ayame., Oshio, Atsushi., Tanaka, Keisuke., Masui, Keita., ve Jonason, Peter, Karl. (2015). Development, reliability and validity of the Japanese version of Dark Triad Dirty Dozen (DTDD-T-J). Japanese Journal of Personality, 1, 26-37.

van der Linden, Sander., ve Rosenthal, Seth, A. (2015). Measuring narcissism with a single question? A replication and extension of the Single-Item Narcissism Scale (SINS). Personality and Individual Differences, 90, 238-241.

Wanous, John. P., Reichers, Arnon. E., ve Hudy, Michael. J. (1997). Overall job satisfaction: how good are single-item measures? J Applied Psychology, 82, 247-252. 